Available online on 15.06 .2020 at http://jddtonline.info
Open Access to Pharmaceutical and Medical Research
(C) 2011-18, publisher and licensee JDDT, This is an Open Access article which permits
unrestricted non-commercial use, provided the original work is properly cited

Open $\odot$ Access

Research Article

\title{
A Study on Prescribing Pattern of Antihypertensive in Chronic Kidney Disease Patients
}

\author{
Riny Thomas*, Sini Sam, Neelaphar P, Shabeeb P, Vishwanath B A² \\ 1 Department of Pharmacy Practice, Aditya Bangalore Institute of Pharmacy Education and Research Bangalore-560064, Karnataka, India \\ 2 Chairman of Aditya Group of Institution, Bengaluru, India
}

\begin{abstract}
Background: Chronic kidney disease causes progressive loss of function which gradually occur overtime leading to decrease in GFR levels leading to dysfunction of renal system. Hypertension is found to be intermingled cause and overlapping complication in CKD. It is important to intervene the progression by controlling the blood pressure to prevent kidney failure by administration of anti-hypertensive. Objectives: To study current trends in anti-hypertensive prescription pattern in CKD patient and to evaluate the concurrent patterns are in adherence according to the guidelines mentioned. Methods: Prospective observational study was undertaken in patients who were satisfying the inclusion criteria and was enrolled into the study conducted for a 6 months period in a tertiary care hospital in Bangalore. Results: 150 CKD patients were examined out of which $72 \%$ prevalence seen in males compared to females $28 \%$. Dual drug therapy was most preferred combination seen in $48 \%$ of the prescriptions. CCB was the most preferred class of drug and least preferred class of drug was ACE. More than $85 \%$ deviation from JNC-8 was seen. $20 \%$ of mono-therapy was found in adherence to JNC-8. Conclusion: A $15 \%$ adherence to JNC- 8 guidelines was observed in the treatment indicating need for clinical pharmacist who play vital role in management of CKD by adherence to JNC-8 to ensure safety, efficacy and rationality.
\end{abstract}

Keywords: Chronic kidney disease, Hypertension, Prescription pattern, JNC-8 guidelines, Compliance, Anti-Hypertensive.

Article Info: Received 21 March 2020; Review Completed 18 May 2020; Accepted 27 May 2020; Available online 15 June 2020

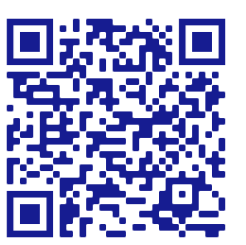

Cite this article as:

Thomas R, Sam S, Neelaphar P, Shabeeb P, Vishwanath BA, A Study on Prescribing Pattern of Antihypertensive in Chronic Kidney Disease Patients, Journal of Drug Delivery and Therapeutics. 2020; 10(3-s):75-81

http://dx.doi.org/10.22270/jddt.v10i3-s.4139

\section{*Address for Correspondence:}

Riny Thomas, Department of Pharmacy Practice, Aditya Bangalore Institute of Pharmacy Education and Research, Bangalore-64, Karnataka, India

\section{INTRODUCTION}

Chronic kidney disease leads to progressive loss of renal function which concomitant on the elevated blood pressure which is managed by administration of Anti-hypertensives. So the main objective of the study is to assess the drug prescription pattern of anti-hypertensive in chronic kidney disease considering the adherence to the JNC-81. According to JNC-8 patients of any age with diabetes or CKD have a goal of less than $140 \mathrm{mmHg}$ systolic and less than $90 \mathrm{mmHg}$ diastolic. The focus of the JNC-8 is to target on the blood pressure values. However, it also provides recommendations to promote the safer use of specific anti-hypertensive agents $^{2}$. There is deviation from the regular therapy of ACE inhibitors and ARBs, other combinations of the 4 agents that can be administered to achieve the ideal goal of blood pressure is also recommended. ACE inhibitors or ARBs are an essential part of hypertensive management in patients up to the age of 75years with CKD, though currently patients with greater than the age of 75years with CKD there is no

ISSN: 2250-1177

[75] authentication supporting renin-angiotensin system inhibitor treatment. While ACE inhibitors or ARBs are been used, CCBs and Thiazide Diuretics can also be considered ${ }^{3}$.

\section{MATERIALS AND METHODS}

The study was a prospective observational study conducted for 6 months period to assess prescribing pattern of antihypertensive in chronic kidney disease was carried out at a tertiary care hospital in Bangalore. The study was carried out on both inpatients and outpatients of the tertiary care hospital, who were currently diagnosed with chronic kidney disease along with hypertension. Pediatric patients, pregnant patients and psychiatric patients were excluded from this study.

All necessary and relevant information were collected from patient case sheet, laboratory data report and treatment chart. A separate data entry format for incorporating patient's details was designed. The format included the details such as Name, Age, Gender, IP number, Data of 
admission, Date of discharge, Patient medical history, Medication history, Laboratory investigation and Treatment chart.

Ethical clearance was obtained for the protocol of the present study which was approved by the ethical committee of Aditya Bangalore Institute for Pharmacy Education and Research and informed consent was agreed by Nephrology Department at the tertiary care hospital,
Statistical Analysis was done by data entered in MS Excel 2007 and analyzed. Descriptive statistics was expressed in terms of actual numbers and percentage was used for data analysis.

\section{RESULTS}

During the 6month period based on the inclusion and exclusion criteria 150 prescriptions were collected from the tertiary care hospital. The demographic characteristics of 150 patients are depicted in Table 1.

Table 1: Prescriptions observations

\begin{tabular}{|c|c|c|c|c|}
\hline Particulars & \multicolumn{2}{|c|}{ Numbers } & \multicolumn{2}{|c|}{ Percentage } \\
\hline \multicolumn{5}{|l|}{ Gender distribution } \\
\hline Number of males patients & \multicolumn{2}{|l|}{107} & \multicolumn{2}{|l|}{$72.33 \%$} \\
\hline Number of males patients & \multicolumn{2}{|l|}{43} & \multicolumn{2}{|l|}{$.28 .66 \%$} \\
\hline Based on Age & Males & Females & Males & Females \\
\hline $20-29$ & 4 & 0 & $3.7 \%$ & 0 \\
\hline $30-39$ & 11 & 4 & $10.28 \%$ & $9.3 \%$ \\
\hline $40-49$ & 12 & 7 & $11.21 \%$ & $16.27 \%$ \\
\hline $50-59$ & 29 & 14 & $27.10 \%$ & $32.55 \%$ \\
\hline $60-69$ & 36 & 14 & $33.64 \%$ & $32.55 \%$ \\
\hline $70-79$ & 11 & 4 & $10.28 \%$ & $9.3 \%$ \\
\hline $80-89$ & 4 & 0 & $3.7 \%$ & 0 \\
\hline $\begin{array}{l}\text { Based on co-morbidity of Diabetes mellitus along } \\
\text { with HTN and CKD }\end{array}$ & Males & Females & Males & Females \\
\hline Diabetic & 61 & 29 & $57 \%$ & $67.44 \%$ \\
\hline Non-Diabetic & 46 & 17 & $42.99 \%$ & $39.53 \%$ \\
\hline \multicolumn{5}{|l|}{ Type of Therapy } \\
\hline Mono therapy & \multicolumn{2}{|l|}{40} & \multicolumn{2}{|l|}{$26.66 \%$} \\
\hline Dual Therapy & \multicolumn{2}{|l|}{72} & \multicolumn{2}{|l|}{$48 \%$} \\
\hline Triple Therapy & \multicolumn{2}{|l|}{22} & \multicolumn{2}{|l|}{$14.66 \%$} \\
\hline Quadruple Therapy & \multicolumn{2}{|l|}{11} & \multicolumn{2}{|l|}{$8.66 \%$} \\
\hline Other (more than 4) & \multicolumn{2}{|l|}{3} & \multicolumn{2}{|l|}{$2 \%$} \\
\hline
\end{tabular}

\section{Monotherapy of Anti-hypertensive Drug}

Out of the 40 Prescriptions (26.66\%) had monotherapy. Out of monotherapy treatment given to patients in the study
$(67.5 \%)$ were given calcium channel blockers followed by 7.5\% Diuretics and Alpha blockers respectively.

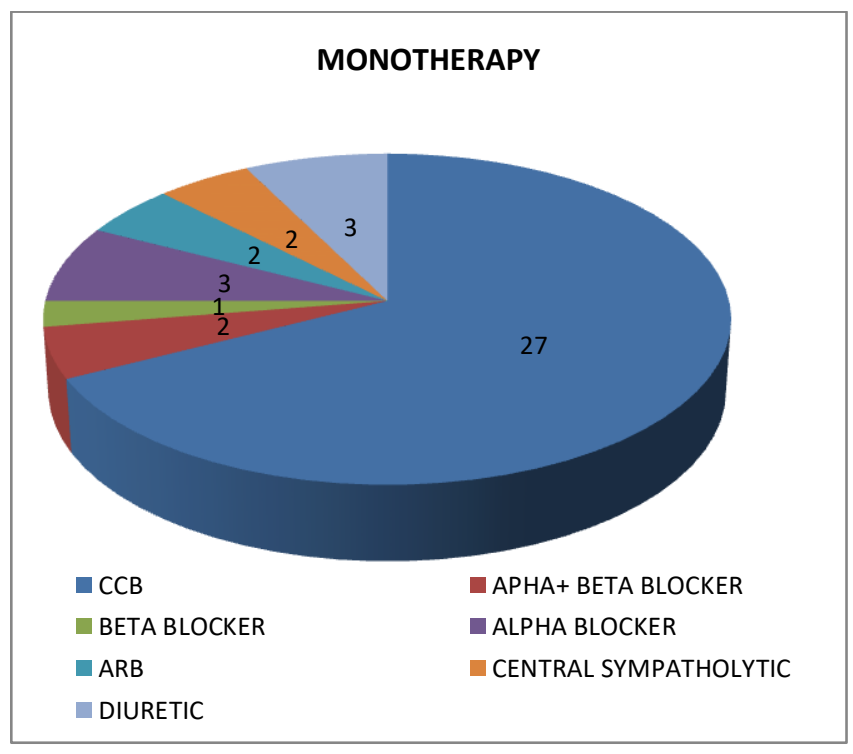

Figure 1: Drugs in Monotheraphy 


\section{Dual therapy of Anti-hypertensives}

Out of the $48 \%$ of dual therapy treatment given to the patients in the study; $27.7 \%$ were treated with CCB+Beta blockers, CCB+Central sympatholytic (20.08\%) and $\mathrm{CCB}+[$ Alpha+Beta blockers](18.05\%) respectively which was found in the prescriptions.

Table 2: Dual Therapy of Anti-hypertensive.

\begin{tabular}{|l|l|l|}
\hline CLASS OF DRUG & NO OF PRESCRIPTION & PERCENTAGE \\
\hline CCB+ APHA+ BETA BLOCKER & 4 & $5.55 \%$ \\
\hline CCB+ DIURETIC & 6 & $8.33 \%$ \\
\hline CCB+ ACE & 2 & $2.77 \%$ \\
\hline CCB+ BETA BLOCKER & 20 & $27.77 \%$ \\
\hline CCB + APHA+ BETA BLOCKER & 13 & $18.05 \%$ \\
\hline CCB+ CENTRAL SYMPATHOLYTIC & 15 & $20.8 \%$ \\
\hline DIURETIC+ BETA BLOCKER & 3 & $4.16 \%$ \\
\hline DIURETIC+ APHA+ BETA BLOCKER & 3 & $2.77 \%$ \\
\hline DIURETIC+ DIURETIC & 1 & $1.3 \%$ \\
\hline ALPHA BLOCKER+ BETA BLOCKER & 2 & $2.77 \%$ \\
\hline CENTRAL SYMPATHOLYTIC+ APHA+ BETA BLOCKER & & $1.3 \%$ \\
\hline CENTRAL SYMPATHOLYTIC+ ALPHA BLOCKER & 1 & $1.3 \%$ \\
\hline BETA BLOCKER + ARB & 1 & $1.3 \%$ \\
\hline
\end{tabular}

\section{Triple therapy of Anti-hypertensive}

Out of the $14.66 \%$ of Triple therapy treatment given to patients in the study it was found that $31.8 \%$ were given
CCB + Beta blockers+ Alpha blocker and CCB + Diuretic +Beta blockers respectively.

Table 3: Triple Therapy of Anti-hypertensive.

\begin{tabular}{|l|l|l|}
\hline CLASS OF DRUG & NO & PERCENTAGE \\
\hline CCB+ APHA BLOCKER + BETA BLOCKER & 7 & $31.8 \%$ \\
\hline CCB+ DIURETIC+ APHA BLOCKER & 2 & $9.09 \%$ \\
\hline CCB+ CENTRAL SYMPATHOLYTIC+ APHA BLOCKER & 2 & $9.09 \%$ \\
\hline CALCIUM CHANNEL +DIURETIC+ BETA BLOCKER & 5 & $22.72 \%$ \\
\hline CALCIUM CHANNEL + CALCIUM CHANNEL +DIURETIC & 1 & $4.54 \%$ \\
\hline CCB+ CENTRAL SYMPATHOLYTIC+ DIURETIC & $9.09 \%$ \\
\hline CCB +CENTRAL SYMPATHOLYTIC+ BETA BLOCKER & 2 & $9.09 \%$ \\
\hline CCB +CENTRAL SYMPATHOLYTIC+ ALPHA+BETA BLOCKER & 2 & $4.54 \%$ \\
\hline CCB +CENTRAL SYMPATHOLYTIC+ARB & 1 & $4.54 \%$ \\
\hline APHA BLOCKER + BETA BLOCKER+ DIURETIC & 1 & $9.09 \%$ \\
\hline
\end{tabular}




\section{Quadruple therapy of Anti-hypertensive}

Out of the $8.66 \%$ of Quadruple therapy treatment given to the patients in the study it was found that $30.76 \%$ were given CCB+Beta blockers+ Alpha blocker + Central Symphatholytic.

Table 4: Quadruple Therapy of Anti-hypertensive.

\begin{tabular}{|l|l|l|}
\hline CLASS OF DRUG & NO OF PRESCRIPTION & PERCENTAGE \\
\hline CCB +CENTRAL SYMPATHOLYTIC+ ALPHA BLOCKER +BETA BLOCKER & \multicolumn{2}{|c|}{$30.76 \%$} \\
\hline CCB +CENTRAL SYMPATHOLYTIC+BETA BLOCKER+ DIURETIC & 1 & $7.69 \%$ \\
\hline CCB +CENTRAL SYMPATHOLYTIC+ARB+ALPHA BLOCKER & 2 & $15.38 \%$ \\
\hline CCB +APHA BLOCKER + BETA BLOCKER+ DIURETIC & 2 & $15.38 \%$ \\
\hline CCB +CENTRAL SYMPATHOLYTIC+ ALPHA BLOCKER +APHA BLOCKER & 2 & $15.38 \%$ \\
\hline CCB +APHA + BETA BLOCKER+ DIURETIC+ CENTRAL SYMPATHOLYTIC & 1 & $7.69 \%$ \\
\hline
\end{tabular}

\section{Others}

In this therapy more than four drug combinations of Antihypertensives were used in 3 prescriptions it was found that in 1 prescription CCB +Beta blockers+ Alpha blocker + Central Symphatholytic+ Diuretics was prescribed and $\mathrm{CCB}+$ Beta blockers+ Alpha blocker + ARB + Diuretic in other 2 prescriptions containing more than four antihypertensives.

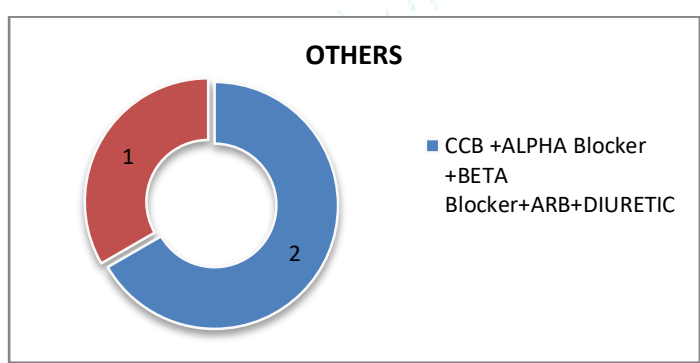

Figure 2: Others (more than 4).

\section{Different class of Prescription}

In management of hypertension in CKD patient with antihypertensives in 150 prescription the most preferred class of drugs was CCB (Calcium channel blocker)which was found in 120 prescriptions followed by Beta blockers in 53 prescription.

Table 5: Different class of Anti-hypertensive

\begin{tabular}{|l|l|}
\hline NAME OF PATIENT & NO OF PRESCRIPTION \\
\hline CALCIUM CHANNEL BLOCKER & 120 \\
\hline APHA BLOCKER & 39 \\
\hline ALPHA+BETA BLOCKER & 12 \\
\hline BETA BLOCKER & 53 \\
\hline DIURETIC & 26 \\
\hline CENTRAL SYMPHATHOLYTIC & 30 \\
\hline ACE & 2 \\
\hline ARB & 7 \\
\hline
\end{tabular}

\section{Calcium Channel Blocker}

In 150 prescription charts assessed most frequently used class of drug was calcium channel blockers which were found in 120 prescriptions:

Table 6: Calcium Channel Blockers in Prescription.

\begin{tabular}{|l|l|l|}
\hline NAME OF DRUG & NO & PERCENTAGE \\
\hline AMLODEPINE & 27 & $22.5 \%$ \\
\hline NIFEDEPINE & 49 & $40.83 \%$ \\
\hline CLINIDIPINE & 42 & $35 \%$ \\
\hline OTHER & 2 & $1.6 \%$ \\
\hline
\end{tabular}

Out of 120 prescription having CCB $(40.83 \%)$ have used Nifedepine followed by Amlodepine (22.5\%), Clinidepine (35\%).

\section{Beta Blocker}

In 150 prescription charts assessed most frequently used class of drug was beta blockers which were found in 53 prescriptions:

Table 7: Beta Blockers in Prescription.

\begin{tabular}{|l|l|l|}
\hline $\begin{array}{l}\text { NAME OF } \\
\text { DRUG NO }\end{array}$ & PERCENTAGE \\
\hline NEBIVOLOL & 8 & $15.08 \%$ \\
\hline METOPROLOL & 37 & $69.81 \%$ \\
\hline BISOPROLOL & 8 & $15.08 \%$ \\
\hline
\end{tabular}

Out of 53 prescriptions having Beta Blocker Metoprolol was the most frequently used Beta blocker in (69.81\%) followed by Bisoprolol and Nebivolol (15.08\%) in 8 prescriptions each.

\section{Different drugs of Prescription}

Out of all prescription obtained from the 150 cases that was collected; the most frequently prescribed drug were Nifedipine(49) followed by Clinidipine(42), Prazosin(38), Metoprolol(37), Clonidine(30), Amlodepine(27) respectively. 
Table 8: Drug in different prescription

\begin{tabular}{|l|l|}
\hline Name of Drug & No of Prescription \\
\hline Nifedipine & 49 \\
\hline Clinidipine & 42 \\
\hline Prazosin & 38 \\
\hline Metoprolol & 37 \\
\hline Clonidine & 30 \\
\hline Amlodepine & 27 \\
\hline Furosemide & 13 \\
\hline Torsemide & 12 \\
\hline Carvedilol & 12 \\
\hline Nebivolol & 8 \\
\hline Bisoprolol & 8 \\
\hline Telmisartan & 3 \\
\hline Losartan & 3 \\
\hline Enalapril & 2 \\
\hline Others & 6 \\
\hline
\end{tabular}

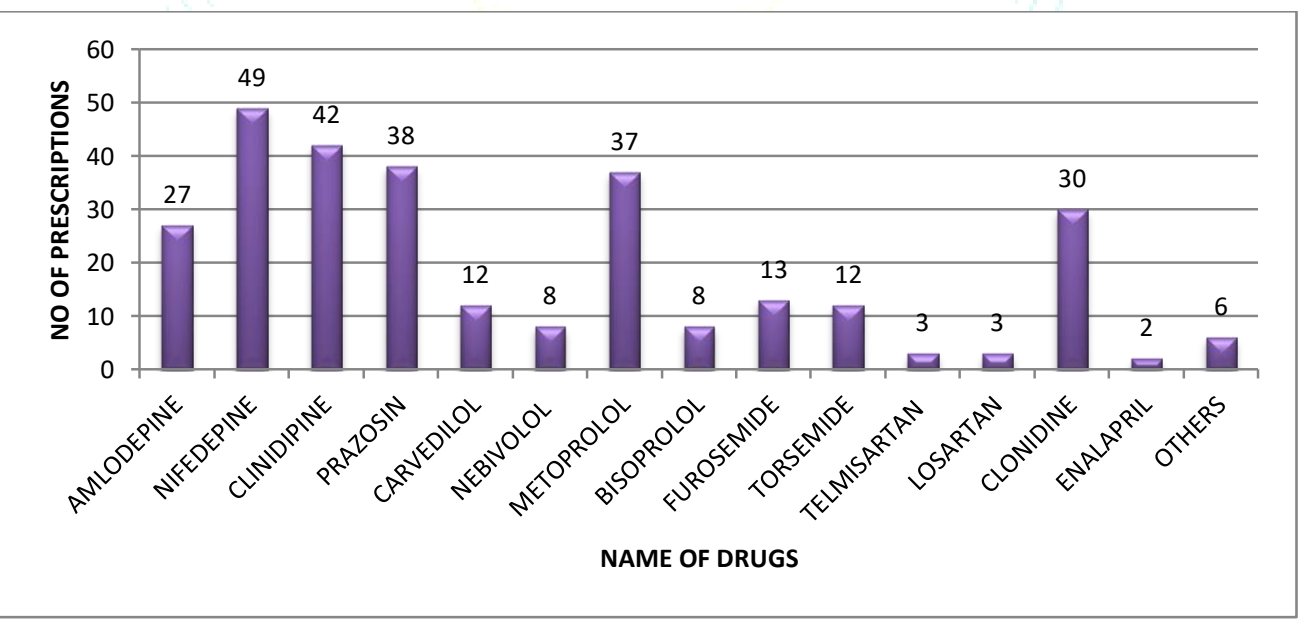

Figure 3: Different types of Drugs.

\section{Prescription comparison with JNC-8}

According to JNC-8 patients with CKD +HTN + Diabetes should be given ACE/ARB/CCB or Diuretic; out of 90 prescriptions under this category adherence to JNC- 8 was seen only in 21 prescriptions. In case of CKD +HTN ACE or ARB should be given and out of 60 prescriptions under this category adherence to JNC- 8 was seen only in 1 prescription.

Table 9: Drug Comparison with JNC-8.

\begin{tabular}{|l|l|l|l|l|}
\hline Comorbidity & $\begin{array}{l}\text { Drugs According to } \\
\text { JNC-8 }\end{array}$ & $\begin{array}{l}\text { Total Number of } \\
\text { Prescrpition }\end{array}$ & $\begin{array}{l}\text { Prescription } \\
\text { Adherance to JNC-8 }\end{array}$ & $\begin{array}{l}\text { Prescription } \\
\text { Adherance to JNC-8 }\end{array}$ \\
\hline $\begin{array}{l}\text { CKD+HTN+ } \\
\text { DIABETES }\end{array}$ & $\begin{array}{l}\text { ACE/ARB/CCB } \\
\text { Diuretic }\end{array}$ & 90 & 21 & 69 \\
\hline CKD+HTN & ACE/ARB & 60 & 1 & 59 \\
\hline
\end{tabular}




\section{Therapy Based Adherences to JNC-8}

The therapy based Adherence to JNC-8 guidelines showed adherence only in case of Monotherapy(19) and Dual Therapy (2) prescriptions.

Table 10: Therapy Comparison with JNC-8.

\begin{tabular}{|c|c|c|c|}
\hline Therapy & Total Prescription & $\begin{array}{l}\text { Prescription Adherence to } \\
\text { JNC-8 }\end{array}$ & $\begin{array}{l}\text { Prescription } \\
\text { Adherence to JNC-8 }\end{array}$ \\
\hline Mono Therapy & 40 & 19 & 21 \\
\hline Dual Therapy & 72 & 2 & 70 \\
\hline Triple Therapy & 22 & $\mathbf{0}$ & 22 \\
\hline Quadruple Therapy & 13 & $\mathbf{0}$ & 13 \\
\hline Others & 3 & $\mathbf{0}$ & 3 \\
\hline
\end{tabular}

\section{Compliance to JNC-8}

The overall adherence of all the prescriptions to JNC- 8 guideline in the study was found to be $14.6 \%$ which indicate irrationality in the prescribing pattern.

Table 11: Compliance with JNC-8.

\begin{tabular}{|l|l|l|}
\hline Prescription Status & No of Prescription & $\%$ of Prescription \\
\hline Prescription Adherence to JNC-8 & 22 & $14.6 \%$ \\
\hline Prescription Non-Adherence to JNC-8 & 128 & $85.3 \%$ \\
\hline
\end{tabular}

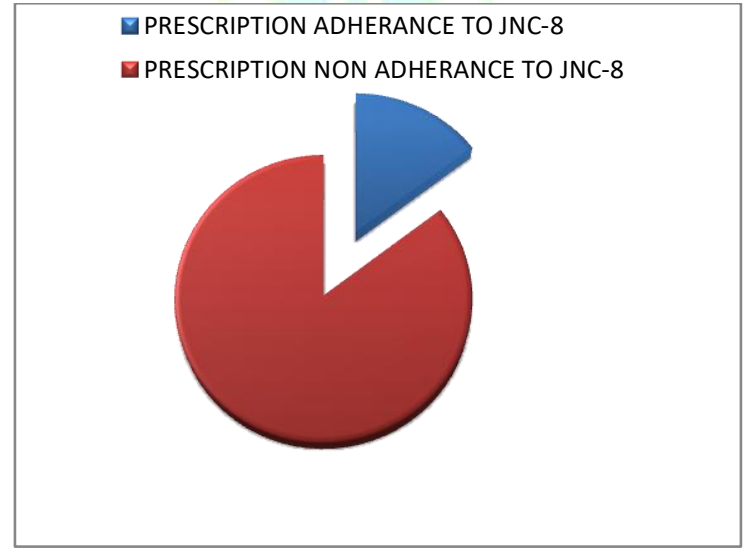

Figure 4: Compliance to JNC-8

\section{DISCCUSION}

The study involved 150 CKD patients with HTN to assess the prescription pattern of anti-hypertensive found that males of age group (60-69years) and (50-59years) are more prone to CKD than females this result is similar to the study conducted by Neethu Joseph et al. ${ }^{4}$ depicts $72 \%$ of patients were male compared to $28 \%$ female and a similar result was found from the study conducted by Pavitra RY et al. ${ }^{5}$. In the current study $60 \%$ of patients had co-morbidity of DM-2 which is supported by the study of Sharminder Kaur et al. 6 and Kalpana Bharani et al. ${ }^{7}$ which showed DM-2 as major co-morbidity which was observed in the patients. In the present study most of the patients were given multi-drugs therapy this result is supported by another study by Ashok Kumar Malpani et al. ${ }^{8}$ that potrayed dual therapy in $78 \%$ of prescription but differ from the study performed by D.Giri Rajasekhar et al. 9 which shows monotherapy as most preferred type of therapy. In the present study most preferred class of drugs was CCB which is supported with the study done by Alwyn p Saju et al.10 and Bhanu Priya B et al.11 who found the similar result. The present study concludes $85 \%$ deviation from JNC-8 guideline which is similar to the non adherence to JNC-8 guidelines study conducted by Sivasakti Raju et al.12 potrayed only $28 \%$ of overall adherence to JNC-8 guidelines confirming physician's non adherence to prescribing pattern in the clinical step confirming need of clinical pharmacist in each department and to make the physician aware which will help to improve adherence to new guidelines in clinical setting.

\section{CONCLUSION}

The study concluded that the treatment of HTN helps to reduce cardiovascular risk associated with the progression of CKD and mortality rate. Medical prescriptions were assessed to find that males of age group (60-69 years) and (50-59 years) are more prone to CKD than the female patients. In this study co-morbidity of DM-2 along with HTN and CKD was seen more prevalent in female $(60 \%)$ compared to males (57\%). In multi-drug therapy dual 
therapy was the most preferred among the other multi-drug therapy. The most widely preferred class after assessing all of the individual prescription was CCB and ARB were the least preferred. According to the results study concludes that there was deviation from JNC-8 guidelines (85\%) indicating non adherence of the physician to the guideline, $20 \%$ of monotherapy were found to have adherence to JNC-8 guidelines. No prescriptions contain ARB +ACE combination and only $2.5 \%$ of dual therapy prescriptions were found to have adhered to JNC-8 guidelines. The study concludes the need of clinical pharmacist who plays a vital role in management of CKD by adherence to JNC -8 guidelines to ensure safety, efficacy and rationality.

\section{ACKNOWLEDGEMENT}

We would like to thank Prof.Ramkumar, (Principal) Dr.Mahesh N M(HOD), teaching and Nonteaching staffs of Aditya Bangalore Institute of Pharmacy Education and Research, Bangalore for all the invaluable support and guidance.

\section{CONFLICT OF INTEREST}

The authors declare no conflict of interest.

\section{ABBREVIATION}

CKD: Chronic Kidney Disease; JNC: Joint National Commission; HTN: Hypertension; DM: Diabetes Mellitus.

\section{REFERENCES}

1. Joseph TD. Chronic Kidney Disease, Pharmacotherapy: A pathological approach, $9^{\text {th }}$ edition. 2008; 633-635

2. Joint National Commission 8(JNC8) guidelines. 2014.

3. Abraham G, Arun KN, Renuka S. Management of hypertension in chronic kidney disease:Consenus statement by an expert panel of Indian nephrologist. Journal of the Association of Physicians of India. February, 2017

4. Neethu J, Yogananda R, Bharathi DR, Varsha P, Sandeep GN. A study on prescription pattern of anti-hypertensive drug in chronic renal failure patients and assessment of medication adherence. International Journal of Pharmceutical Science. 2017; 45(2):72-75.

5. Pavitra RY, Geetha M, Rajeev A, Somshekar HS. Drug Utilisation pattern of anti-hypertensive drug in chronic kidney disease in a tertiary care hospital. IOSR Jornal of Dental and Medicine Science. 2014; 13(11):23-7.

6. Sharminder K, Seema G, Dinesh K, Mohan L, Zahid G. Prescribing pattern Anti-hypertensive Drug in a tertiary care hospital in Jammu-A descriptive study. Clinical Pharmacy. 2012; 17(4):38-41.

7. Kalpana B, Rajesh B, Rubina V, Chhaya G. Drug Utilisation pattern of anti-hypertensive drug in chronic kidney disease stage -5 patient in a tertiary care hospital of central India. International Journal of Basic and Clinical Pharmacology. 2018; 7(7):1411-4.

8. Ashok KM, Manjunath W, Palash P, Thella MC. Study of Prescribing pattern Anti-hypertensive Drug and Evaluation of the Prescription with JNC 8 Guidelines in North Karnataka. Indian Journal of Pharmacy Practice. 2018; 11(4):193-6.

9. Giri RD, Guru PD, Chandrakanth P. Prescribing pattern Antihypertensive Drug based on compelling indicators. International Journal of Pharamceutical Science. 2016; 8(2):72-5.

10. Alwyn PS, Ankur CE, Maheswari E, Gurudev KC. Prescribing pattern and cost effectiveness analysis of anti-hypertensive drug in chronic kidney disease patient. European Journal of Pharmaceutical and Medical Research. 2016; 3(1):219-25.

11. Bhanu PB, Basavanna PL. Pattern of anti-hypertensive drug utilisation in chronic kidney disease patient in dialysis unit of tertiary care hospital. International Journal of Biomedical Research. 2015; 6(04):251-4.

12. Sivasakthi R, Sam S, Nityan K, Anna CJ, Venkatanarayanan. Assessment of Prescribing Pattern for Hypertension and Comparison with JNC-8 Guidelines-Proposed intervention by Clinical Pharmacist. J Young Pharm. 2016; 8(2):133-5. 